\title{
Fibrin-associated large B-cell lymphoma: first case report within a cerebral artery aneurysm and literature review
}

\author{
Magda Zanelli ${ }^{1}$, Maurizio Zizzo ${ }^{2,3^{*}}$ D, Marco Montanaro ${ }^{4}$, Vito Gomes ${ }^{5}$, Giovanni Martino ${ }^{6}$, Loredana De Marco ${ }^{1}$, \\ Giulio Fraternali Orcioni ${ }^{7}$, Maria Paola Martelli ${ }^{6}$ and Stefano Ascani ${ }^{8}$
}

\begin{abstract}
Background: Fibrin-associated diffuse large B-cell lymphoma (FA-DLBCL) is a rare Epstein-Barr virus (EBV) positive lymphoproliferative disorder included in the current World Health Organization (WHO) classification. It arises within fibrinous material in the context of hematomas, pseudocysts, cardiac myxoma or in relation with prosthetic devices. In these clinical settings the diagnosis requires an high index of suspicion, because it does not form a mass itself, being composed of small foci of neoplastic cells. Despite overlapping features with diffuse large B-cell lymphoma associated with chronic inflammation, it deserves a separate classification, being not mass-forming and often following an indolent course.
\end{abstract}

Case presentation: A 64-year-old immunocompetent woman required medical care for cerebral hemorrhage. Computed Tomography (CT) angiography identified an aneurysm in the left middle cerebral artery. A FA-DLBCL was incidentally identified within thrombotic material in the context of the arterial aneurysm. After surgical removal, it followed a benign course with no further treatment.

Conclusions: The current case represents the first report of FA-DLBCL identified in a cerebral artery aneurysm, expanding the clinicopathologic spectrum of this rare entity. A complete literature review is additionally made.

Keywords: Fibrin, B-cell, Lymphoma, Epstein-Barr virus

\section{Background}

In the current WHO classification, diffuse large B-cell lymphoma associated with chronic inflammation (DLBCL-CI) is defined as an EBV-driven neoplasm, occurring in longstanding chronic inflammation in restricted spaces [1]. The prototype is pyothoraxassociated lymphoma (PAL) arising in patients with a long history of pyothorax, following artificial pneumothorax as treatment for tuberculosis [1]. Recently, another EBV-related entity has been included among DLBCL-CI, but renamed fibrin-associated diffuse large

\footnotetext{
* Correspondence: zizzomaurizio@gmail.com

${ }^{2}$ Surgical Oncology Unit, Azienda Unità Sanitaria Locale-IRCCS di Reggio Emilia, Reggio Emilia, Italy

${ }^{3}$ Clinical and Experimental Medicine PhD Program, University of Modena and Reggio Emilia, Modena, Italy

Full list of author information is available at the end of the article
}

B-cell lymphoma (FA-DLBCL) because it develops within fibrinous material [1].

It has been reported in association with pseudocysts, cardiac myxoma, valve prosthesis, fibrin thrombus, synthetic tube graft, hydrocele, metallic implants, and chronic subdural hematoma [1-25]. Differently from PAL, it does not form masses, being composed of rare neoplastic cells and it represents often an incidental finding [1]. Whereas PAL follows an aggressive course, the majority of FA-DLBCL behave favorably and may not require therapies other than surgery. Rare cases with persistent or localized recurrent disease have been described [9]. Only one case with a poor outcome has been reported so far [24]. We present the first report of FA-DLBCL incidentally disclosed in a cerebral artery aneurysm, widening the clinicopathological spectrum of this rare entity. 


\section{Case presentation}

A 64-year-old immunocompetent woman was referred to hospital for cerebral hemorrhage in left temporalparietal region. CT angiography detected an aneurysm in the distal segment of left middle cerebral artery. Tiny fragments of brain tissue together with partially organized thrombus were surgically removed. Histologically, it was identified an artery, with an interrupted wall, occluded by thrombotic material (Fig. 1). Small foci of large atypical lymphoid cells (Fig. 1, inset; Fig. 2) were disclosed within thrombus. The cells were positive for PAX5 (Fig. 2, inset left), CD30 and MUM1 (Fig. 2, inset right) with partial expression of CD79 $\alpha$ and CD20. The proliferative index (Fig. 3 a) was high (Ki67 about 90\%). The cells expressed LMP-1 and were diffusely positive for EBV by in situ hybridization for EBV-encoded RNA (EBER) (Fig. 3, b). Clonal immunoglobulin heavy chain (IGH) rearrangement was detected. A fibrin-associated diffuse large B-cell lymphoma was diagnosed. Staging procedures (CT scan and bone marrow biopsy) were negative. Three months later, CT scan showed an almost complete hemorrhage resorption. No further treatment was given. The patient is alive, free of disease at 8 months from diagnosis.

\section{Discussion and conclusions}

FA-DLBCL is a rare EBV-associated B-cell lymphoma included in the current WHO classification, in the chapter of DLBCL-CI [1]. Differently from DLBCL-CI, it is not mass-forming and therefore disclosed incidentally on histological evaluation of surgical specimens removed for other diseases [1]. Forty seven cases, including our, have been reported so far [1-25].

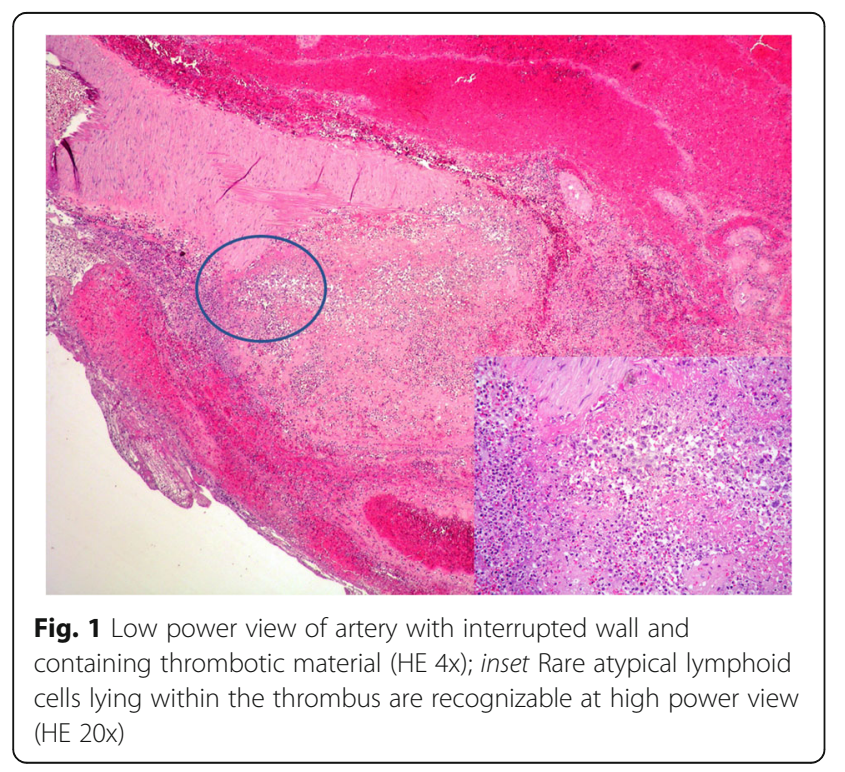

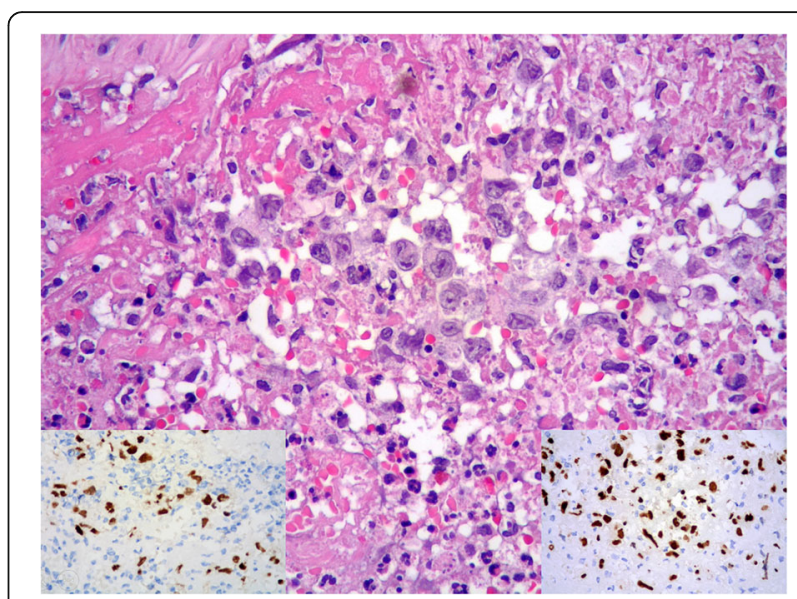

Fig. 2 High power detail of large lymphoid cells (HE 40x); inset left PAX5 positivity of lymphoid cells; inset right MUM1 expression of lymphoid cells

Clinicopathological data are summarized in Table 1. It shows male predominance with a wide age range. No ethnic differences have been apparently identified so far [9]. All cases, except 2 [9], occurred in immunocompetent individuals, presenting with different symptoms, depending on the underlying conditions in which FA-DLBCL occurred.

Cardiac myxoma represents one of the most frequent site of occurrence with 14 cases identified, whereas only occasional cases arose in atrial thrombi and within mixomatous valve degeneration. Some cases have been identified in association with prosthetic devices such as endovascular graft, cardiac valve prosthesis and metallic implant. Time from placement of devices to lymphoma diagnosis is extremely variable, ranging from 1 to more than 20 years. A rather frequent site of presentation is represented by pseudocysts, with a total of 10 cases, in different organs (adrenal gland, spleen, kidney, retroperitoneum, testis). Single descriptions at unusual sites as within testicular hydrocele, ovarian teratoma and testicular hematoma are also reported. The intracranial location appears to be rare, with only 4 cases within chronic subdural hematomas [9, 22-24] and 1 within an arachnoid cyst [25]. Our case represents the first report in a patient with a brain hemorrhage and incidentally identified within thrombotic material in a cerebral artery aneurysm. Notably in all cases evaluated (45/47) staging workup at diagnosis revealed no other sites of disease.

Histologically all cases were remarkably similar and found incidentally, being composed of microscopic foci of large lymphoid cells, embedded within fibrin and not invading adjacent tissue structures. Most cases had a non-germinal center B-cell phenotype and high 


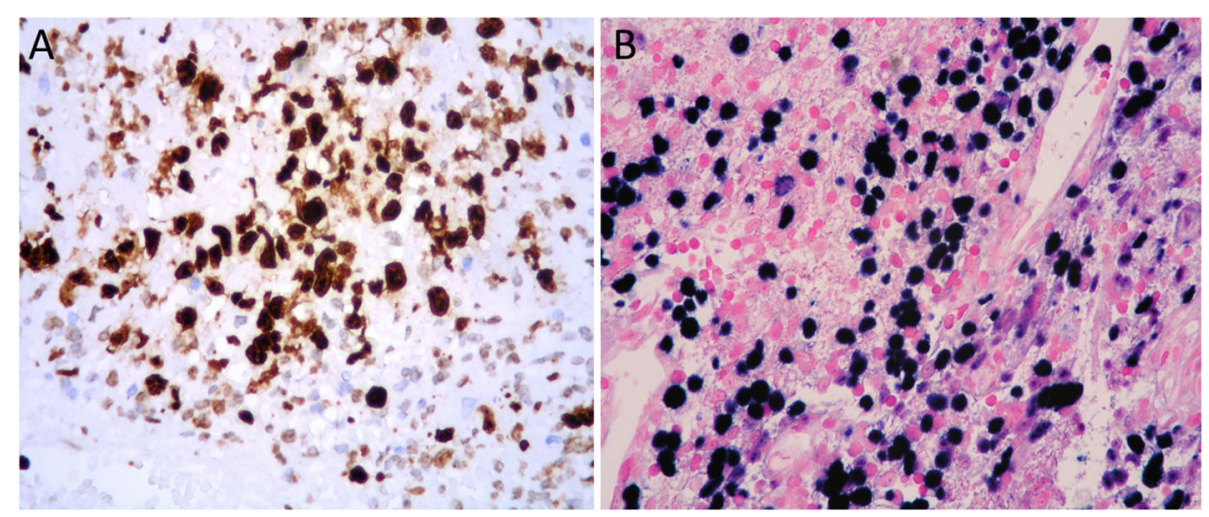

Fig. 3 High proliferative index (Ki67) (a); Epstein-Barr virus positivity in large-sized cells by in situ hybridization for EBV-encoded RNA (EBER) (b)

proliferative index. A strong association with EBV infection is present; as 41/43 evaluated were positive for EBV by EBER-ISH. Notably a type III EBV latency profile, with positivity for LMP-1 and Epstein-Barr nuclear antigen-2 (EBNA-2) was found in most cases (18/22 tested). Type III latency of EBV infection is the hallmark of lymphoproliferative disorders arising in the setting of severe immunosuppression. EBV-infected cells expressing EBNA-2 do not survive in immunocompetent individuals, because destroyed by cytotoxic T-lymphocytes. As patients with FA-DLBCL are immunocompetent, it has been assumed that the restricted environment where FA-DLBCL occurs, allows the EBV-infected B-cells to escape T-cell surveillance [9]. Clonal immunoglobulin rearrangement was identified in most cases evaluated. None of the cases tested by fluorescence in situ hybridization (FISH) showed cMYC, BCL6 and/or BCL2 rearrangements or amplifications: a rather striking difference from PAL, presenting MYC amplification in $80 \%$ of cases [9]. Clinical course of FA-DLBCL is commonly indolent. Remarkably of 36 cases with available follow-up, 30 pursued a benign course, with no evidence of disease from 1 to 130 months. Treatment is variable, although surgery alone often represents the treatment of choice. Sixteen/30 cases were treated with surgery alone, 11 with surgery plus chemotherapy, 1 with surgery plus radiotherapy, 1 with surgery plus immunotherapy, and 1 with surgery plus chemotherapy and radiotherapy. All cases arising within pseudocysts behaved favorably. Local recurrences or persistent disease were seen only in isolated cases in which the primary disease had arisen either within an atrial myxoma (1) or at sites of previous vascular graft (2) [9]. The recurrent or persistent disease presented close to the site initially involved. Two/3 patients died of thromboembolic disease and 1 is alive with stable and localized disease. It has been hypothesized that FA-DLBCL arising at cardiac or vascular sites can recur or persist more easily than cases occurring in sites more amenable to complete surgical removal [9]. Kameda et al reported the unique case with an aggressive course, occurring in an elderly patient within a chronic subdural hematoma observed conservatively [1, 24]. Seven months later, a de novo brain mass developed beneath the hematoma [24]. After surgical removal, the neoplasm within the subdural hematoma appeared consistent with FA-DLBCL and the brain mass was an EBV-positive DLBCL [24]. The authors hypothesized that the lymphoid process developed in the hematoma before infiltrating the brain parenchyma [24]. Once the lymphoma infiltrates outside the subdural hematoma, the prognosis becomes poor [1]. FA-DLBCL shares similarities with breast implantassociated anaplastic large B-cell lymphoma (BIAALCL), although the latter is a T/null lymphoma, not EBV-related [1]. Both entities portend a worse prognosis, when infiltrate the surrounding tissues outside the restricted space of origin.

Our case arose in a previously unreported setting, being identified in a cerebral artery aneurysm of a patient with a brain hemorrhage. The disease was totally confined within thrombotic material occluding the artery. After surgical removal, it pursued a benign course with no additional treatment.

In conclusion, FA-DLBCL is a rare EBV-related lymphoproliferative disorder, arising within fibrinous material in different clinical settings. Intracranial location is very rare. This represents the first report within a cerebral artery aneurysm. Diagnosis can be tricky, being FADLBCL not mass-forming and composed of tiny neoplastic foci. Clinical behavior is mostly indolent. The limited number of FA-DLBCL reported so far makes difficult to draw definitive conclusion regarding the best treatment. Further cases with longer follow-up would help to adopt the most appropriate therapeutic options for each individual patient. 
Zanelli et al. BMC Cancer ～～(2019) 19:916

Page 4 of 9

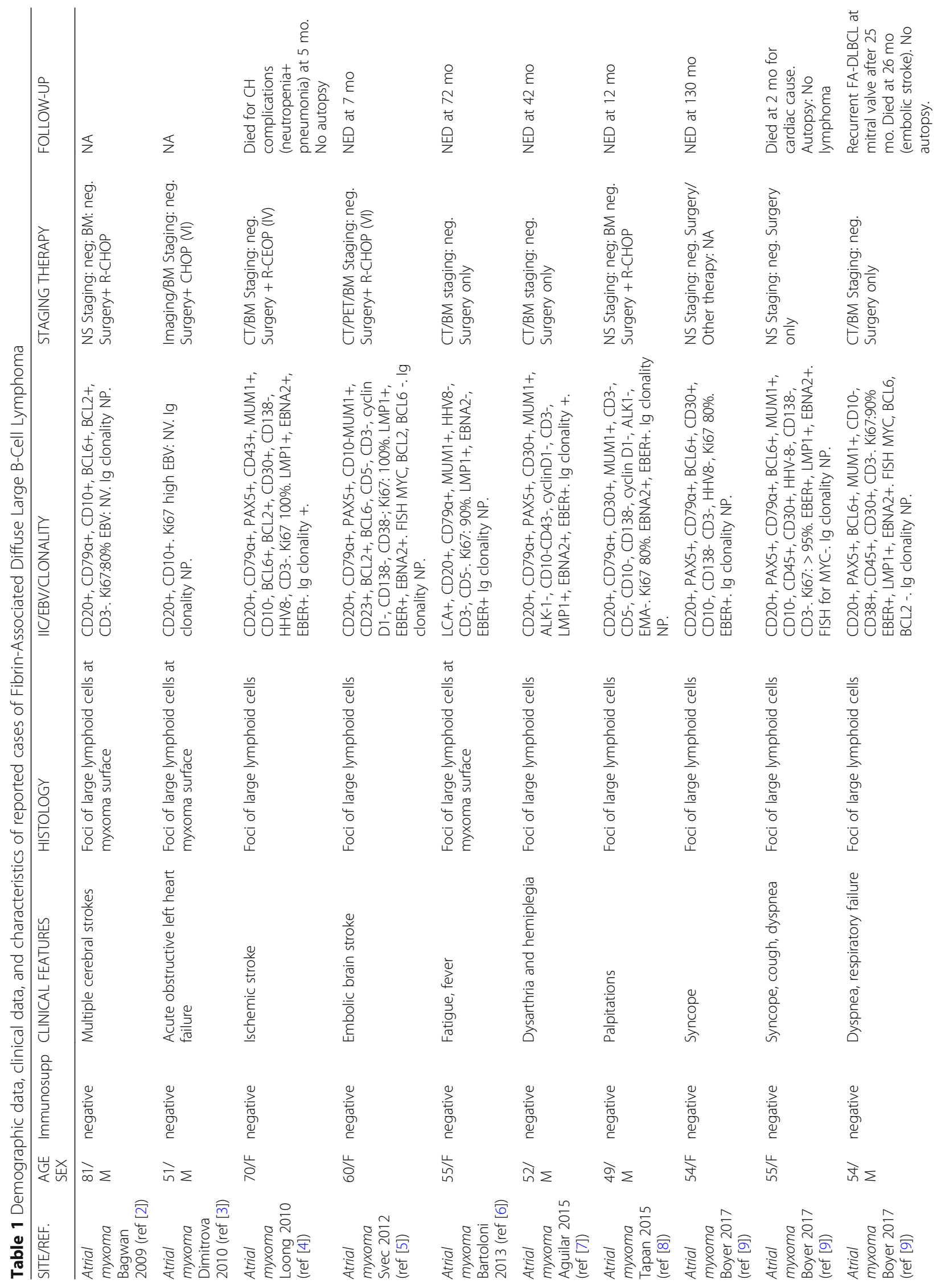




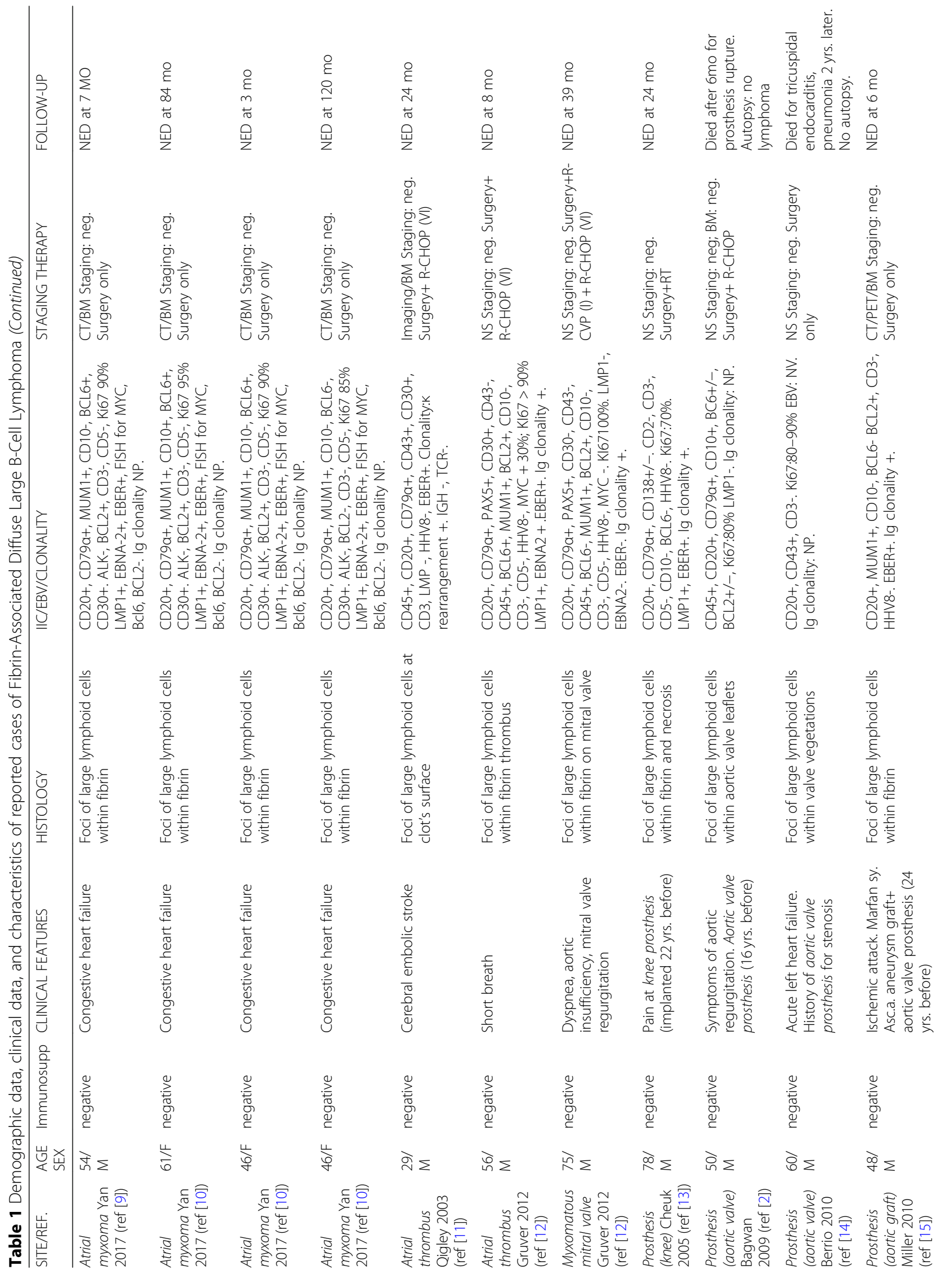




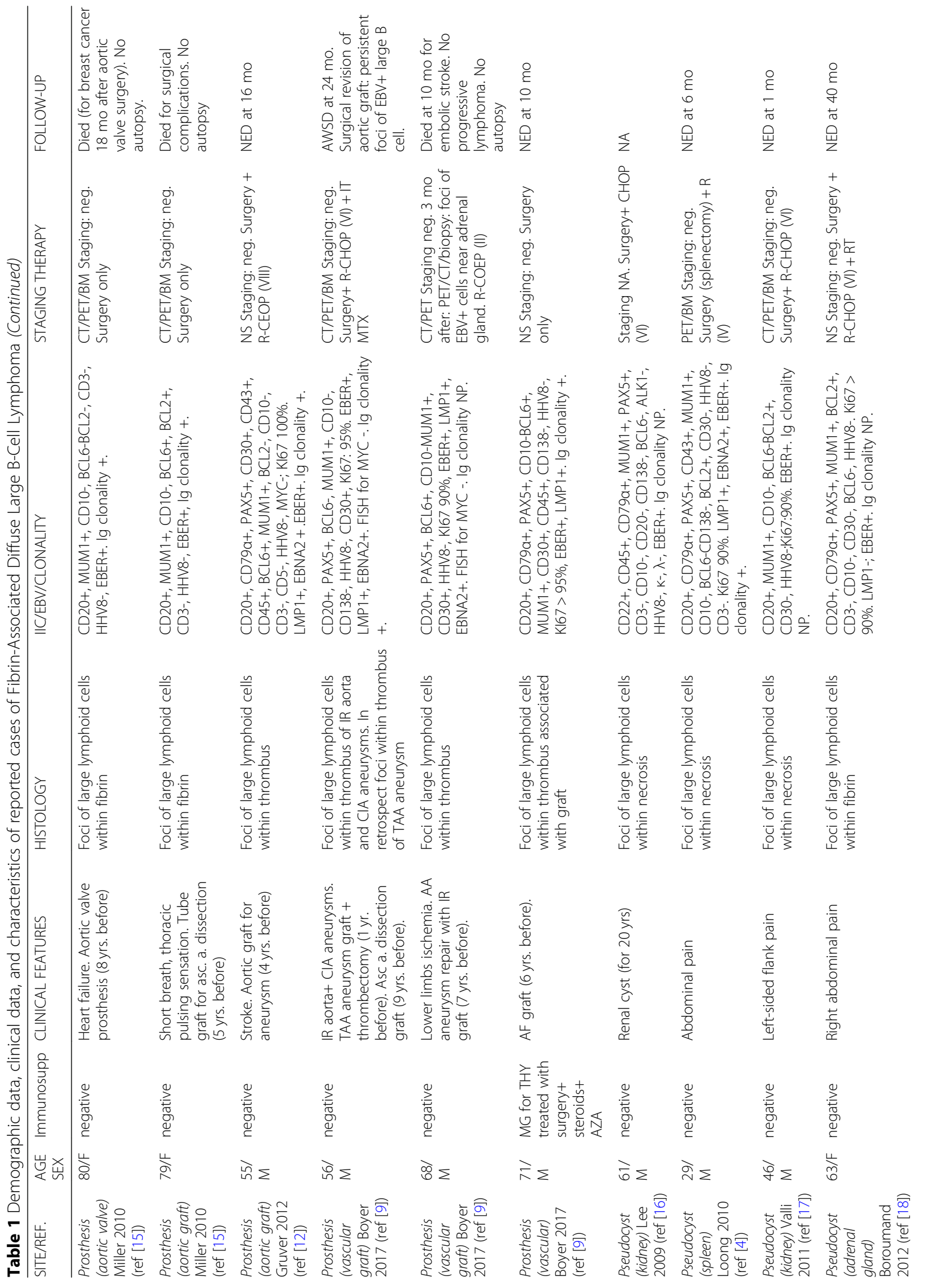




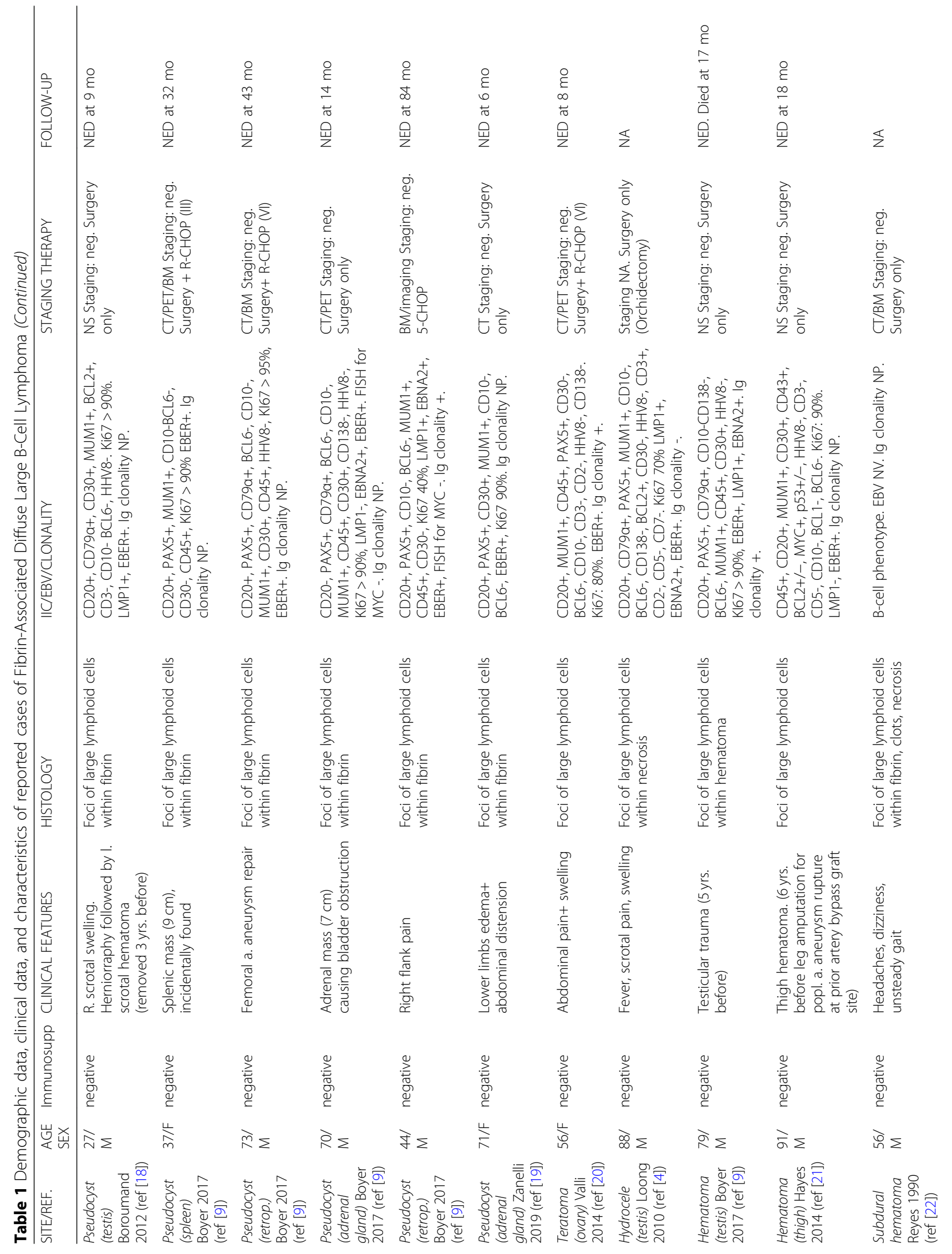




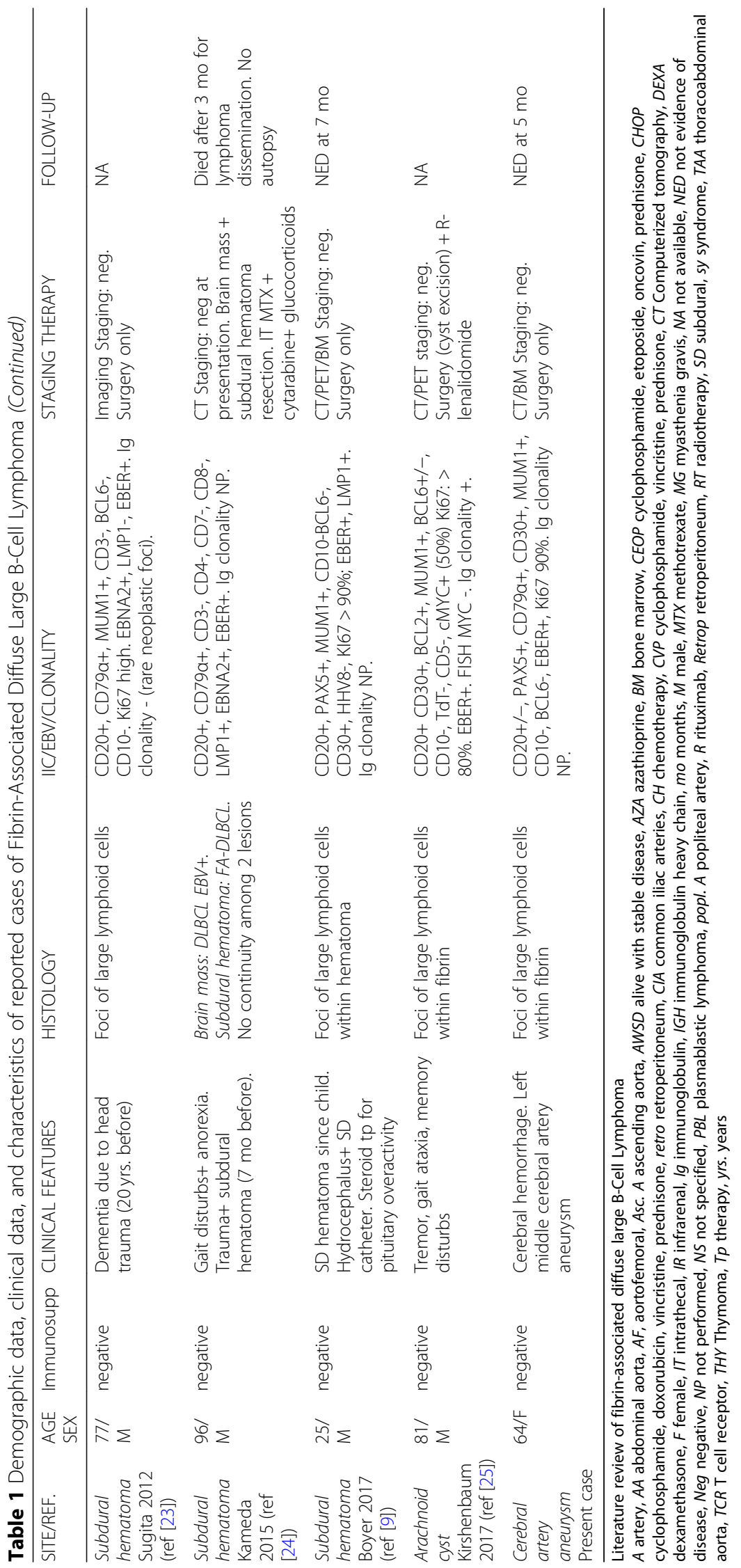




\section{Abbreviations}

BIA-ALCL: Breast implant-associated anaplastic large B-cell lymphoma; CT: Computed Tomography; DLBCL-Cl: Diffuse large B-cell lymphoma associated with chronic inflammation; EBER: EBV-encoded RNA; EBV: EpsteinBarr virus; FA-DLBCL: Fibrin-associated diffuse large B-cell lymphoma; PAL: Pyothorax-associated lymphoma; WHO: World Health Organization

\section{Acknowledgements}

None.

\section{Authors' contributions}

ZaM wrote the manuscript and performed literature review; AS performed histopathological examination and designed the study; MM studied the patient; GV, MG, DL, FOG, MMP performed literature review; ZiM was involved in review, editing and validation of the manuscript. All authors have read and approved the manuscript.

\section{Funding}

The authors have no financial ties to disclose.

\section{Availability of data and materials}

All the original data supporting our research are described in the Case presentation section and in the figures' legends.

\section{Ethics approval and consent to participate}

Local ethics committee (Comitato Etico dell'Area Vasta Emilia Nord, Italy) ruled that no formal ethics approval was required in this particular case. Patient gave consent to participate.

\section{Consent for publication}

Written informed consent was obtained from patient for publication of this Case Report and any accompanying images. A copy of the written consent is available for review by the Editor-in-Chief of this journal.

\section{Competing interests}

The authors declare they have no competing interests.

\section{Author details}

${ }^{1}$ Pathology Unit, Azienda Unità Sanitaria Locale-IRCCS Reggio Emilia, Reggio Emilia, Italy. ${ }^{2}$ Surgical Oncology Unit, Azienda Unità Sanitaria Locale-IRCCS di Reggio Emilia, Reggio Emilia, Italy. ${ }^{3}$ Clinical and Experimental Medicine PhD Program, University of Modena and Reggio Emilia, Modena, Italy. ${ }^{4}$ Hematology Unit, Ospedale di Belcolle, Viterbo, Italy. ${ }^{5}$ Pathology Unit, Ospedale di Belcolle, Viterbo, Italy. ${ }^{6}$ Hematology Unit, CREO, Azienda Ospedaliera di Perugia, University of Perugia, Perugia, Italy. ${ }^{7}$ Pathology Unit, Azienda Ospedaliera S. Croce e Carle, Cuneo, Italy. ${ }^{8}$ Pathology Unit, Ospedale di Terni, University of Perugia, Perugia, Italy.

Received: 2 July 2019 Accepted: 2 September 2019

Published online: 13 September 2019

\section{References}

1. Swerdlow SH, Campo E, Harris NL, Jaffe ES, Pileri SA, Stein H, Thiele J, Arber DA, Hasserjian RP, Le Beau MM, Orazi A, Siebert R, editors. WHO classification of tumours of hematopoietic and lymphoid tissues. Lyon: IARC; 2017

2. Bagwan IN, Desai S, Wotherspoon A, Sheppard MN. Usual presentation of primary cardiac lymphoma. Interact Cardiovasc Thorac Surg. 2009;9:127-9.

3. Dimitrova KR, Hoffman DM, Geller CM, Thiagariah P, Master J, Berger M, Tranbaugh RF. Malignant B-cell lymphoma arising in a large, left atrial mass. Ann Thorac Surg. 2010;89:626-9.

4. Loong F, Chan ACL, Ho BCS, Chau YP, Lee HY, Cheuk W, Yuen WK, Ng WS, Cheung HL, Chan JKC. Diffuse large B-cell lymphoma associated with chronic inflammation as an incidental finding and new clinical scenarios. Mod Pathol. 2010;23:493-501

5. Svec A, Rangaiah M, Giles M, Jaksa R, Mc Aulay KA. EBV+ diffuse large B-cell lymphoma arising within atrial myxoma. An example of a distinct primary EBV+ DLBCL of immunocompetent patients. Pathol Res Pract. 2012;208:172-6

6. Bartoloni G, Pucci A, Giorlandino A, Berretta M, Mignosa C, Italia F, Carbone A, Canzonieri V. Incidental Epstein-Barr virus associated atypical lymphoid proliferation arising in a left atrial myxoma: a case of long survival without any postsurgical treatment and review of the literature. Cardiovasc Pathol. 2013:22:5-10.

7. Aguilar C, Beltran B, Quinones P, Carbajal T, Vilcapaza J, Yabar A, Segura P, Quintanilla-Martinez L, Miranda RN, Castillo JJ. Large B-cell lymphoma arising in cardiac myxoma or intracardiac fibrinous mass. A localized lymphoma usually associated with Epstein-Varr virus? Cardiovasc Pathol. 2015;24:60-4.

8. Tapan U, Pestana JB, Lee JC, Lerner A. Epstein-Barr virus-associated diffuse large B-cell lymphoma arising in atrial myxoma: a proposal for a modified therapeutic approach. Leuk Lymphoma. 2015;56(2):505-7.

9. Boyer DF, McKelvie PA, de Leval L, Edlefsen KL, Ko YH, Aberman ZA, Kovach AE, Masih A, Nishino HT, Weiss LM, Meeker AK, Nardi V, Palisoc M, Shao L, Pittaluga S, Ferry JA, Lee Harris N, Sohani AR. Fibrin-associtaed EBV-positive large B-cell lymphoma. An indolent neoplasm with features distinct from diffuse large B-cell lymphoma associated with chronic inflammation. Am J Surg Pathol. 2017:41:299-312

10. Yan J, Luo D, Zhang F, He J, Yao S, Luo X, Hu F, Chen Y, Fu L, Xu J, Liu Y. Diffuse large B-cell lymphoma associated with chronic inflammation arising within atrial myxoma: aggressive histological but indolent clinical behaviour. Histopathology. 2017;71:951-9.

11. Quiley MM, Schwartzman E, Boswell PD, Christensen RL, Gleason LA, Sharpe RW, d'Amato TA. A unique atrial primary cardiac lymphoma mimicking myxoma presenting with embolic stroke: a case report. Blood. 2003;101:4708-10.

12. Gruver AM, Huba MA, Dogan A, His ED. Fibrin-associated large B-cel lymphoma. Part of the spectrum of cardiac lymphomas. Am J Surg Pathol. 2012:36:1527-37.

13. Cheuk W, Chan ACL, Chan JKC, Lau GTC, Chan VNH, Yiu HHY. Metallic implantassociated lymphoma. A distinct subgroup of large B-cell lymphoma related to pyothorax-associated lymphoma? Am J Surg Pathol. 2005;29:832-6.

14. Berrio $\mathrm{G}$, Suryadevara $\mathrm{A}$, Singh $\mathrm{NK}$, Wesly $\mathrm{OH}$. Diffuse large B-cell lymphoma in an aortic valve allograft. Tex Heart Inst J. 2010;37(4):492-3.

15. Miller DV, Firchau DJ, Mc Clure RF, Kurtin PJ, Feldman AL. Epstein-Barr virusassociated diffuse large B-cell lymphoma arising on cardiac prosthesis. Am J Surg Pathol. 2010;34:377-84.

16. Lee MC, Aron M, His ED, Herts BR, Pohlman B, Gill IS. Age-related EpsteinBarr virus-associated lymphoproliferative disorder presenting as renal mass. Urology. 2009:74(3):505-8.

17. Valli R, Piana S, Capodanno I, Cavazza A. Diffuse large B-cell lymphoma associated with chronic inflammation arising in a renal pseudocyst. Int J Surg Pathol. 2011;19(1):117-9.

18. Boroumand N, Ly TL, Sonstein J, Medeiros LJ. Microscopic diffuse large Bcell lymphoma (DLBCL) occurring in pseudocysts. Do these tumors belong to the category of DLBCL associated with chronic inflammation?. Am J. Surg Pathol. 2012:36:1074-80

19. Zanelli M, Zizzo M, De Marco L, Bisagni A, Ascani S. Fibrin-associated diffuse large B-cell lymphoma. Br J Haematol. 2019;185(3):397.

20. Valli R, Froio E, Alvarez De Celis MI, Mandato VD, Piana S. Diffuse large B-cell lymphoma occurring in an ovarian cystica teratoma: expanding the spectrum of large B-cell lymphoma associated with chronic inflammation. Hum Pathol. 2014:45:2507-11.

21. Hayes C, Alkan S, Kitahara S. Indolent fibrin-associated EBV-positive large Bcell lymphoproliferative disorder in a lower extremity aneurysmal hematoma: a case report. J Hematop. 2014;7:139-43.

22. Reyes MG, Homsi MF, Mangkornkanong M, Stone J, Glick RP. Malignant lymphoma presenting as a chronic subdural hematoma. Surg Neurol. 1990;33:35-6.

23. Sugita Y, Ohta M, Ohshima K, Niino D, Nakamura Y, Okada Y, Nakashima S Epstein-Barr virus-positive lymphoproliferative disorder associated with old organized chronic subdural hematoma. Pathol Int. 2012;62:412-7.

24. Kameda K, Shono T, Takagishi S, Kono S, Aoki T, Ito Y, Kamimura T, Sugita Y, Ohshima K. Epstein-Barr virus-positive diffuse large B-cell primary central nervous system lymphoma associated with organized chronic subdural hematoma: a case report and review of the literature. Pathol Int. 2015;65:138-43.

25. Kirschenbaum D, Prommel P, Vasella F, Haralambleva E, Maggio EM, Reisch R, Beer M, Camenisch U, Rushing EJ. Fibrin-associated diffuse large B-cell lymphoma in a hemorrhagic cranial arachnoid cyst. Acta Neuropatol Commun. 2017:5:60.

\section{Publisher's Note}

Springer Nature remains neutral with regard to jurisdictional claims in published maps and institutional affiliations. 